\title{
Retrospective Cohort Study on Association of Lung Cancer with Pulmonary Tuberculosis
}

\author{
Y.T. Gao', W. Zheng', F. Jin', J. Peng'2, S.L. Zhu' ${ }^{2}$ and Z.X. Wang' \\ 1. Shanghai Cancer Institute, Shanghai, China \\ 2. Shanghai Antituberculosis Centre, Shanghai, China
}

\begin{abstract}
A retrospective cohort study among tuberculosis patients registered in Shanghai TB Registry since 1972 was carried out during 1987-89 for testing the hypothesis on association of lung cancer with pulmonary tuberculosis. A total of 30,373 cases (male: 19,709 and female: 10,664) of pulmonary tuberculosis patients born before 1 January 1957 and resided in Shanghai urban were followed up until 1986. The SMRs for lung cancer were 1.38 and 2.73 in males and females, respectively, both of which were statistically significant. When the risk was adjusted by smoking, the adjusted SMRs for lung cancer were 1.72 (95\% Cl: 1.11-2.53) in males and 2.79 (95\% Cl: 1.79-4.14) in females. The elevated risk of lung cancer among tuberculosis patients was irrelevant to smoking. INH treatment and $\mathrm{X}$-ray exposure can not be explained for this higher risk.
\end{abstract}

Pulmonary tuberculosis, Lung cancer, Cohort study, Smoking

\section{INTRODUCTION}

In a population-based case-control study on lung cancer in Shanghai urban involving interviews during 1984-86 with 1405 cancer patients and 1495 controls, a significant 50\% elevation in the risk of lung cancer, adjusted for cigarette smoking, was observed among persons who had a history of tuberculosis ${ }^{(1)}$. For testing the hypothesis on association of lung cancer with pulmonary tuberculosis generated by the case-control study, a retrospective cohort study among persons, who had a clinical manifestation of pulmonary tuberculosis, was carried out in Shanghai urban during 1987-89.

\section{MATERIALS AND METHODS}

The system of registration of tuberculosis patients in Shanghai area has been established since 1958 by the Shanghai Antituberculosis Network. Medical workers of the Network 
periodically interview TB patients until recovery and fill in a unified card for each case with general and medical information relevant to the patient including medical measures for diagnosis and treatment such as intake of antituberculosis drugs, chest $\mathrm{X}$-ray exposure, etc. The registration cards kept by the Network were used for this study.

Since the completeness of registration and quality of keeping of registration cards during late 1960s was seriously influenced by the special situation of that time, many cards filled in before 1972 have been lost, so only the cards on cases of pulmonary tuberculosis registered since 1972 were used in the study. During the period from 1 January 1972 to 31 December 1986 a total of 32,968 cases of pulmonary tuberculosis born before 1 January 1957 and resided in Shanghai urban were registered and used as the cohort members.

The relevant information on each case was transcribed from card into an individual questionnaire. Cases or relatives of the cases were interviewed at home by trained interviewers for checking information obtained from cards and collecting information on smoking history of the cases. Information on cause of death was also collected when case died. After coding the data were input into the computer for processing and analyzing.

The standardized mortality ratio (SMR) with $95 \%$ confidence interval (CI) was used for measuring association of lung cancer with pulmonary tuberculosis in the study. The agesex-specific mortality rates for lung cancer among general population in Shanghai urban during three periods $(1972-1976,1977-1981,1982-1986)$ were used as standard for calculating SMRs. Trend test was used for the data grouped into more than two exposure groups.

In order to avoid the bias stemmed from mistake in diagnosis of lung cancer of early stage as pulmonary tuberculosis, all deaths occurred within three years after diagnosis of lung tuberculosis as well as the observed person-years for first three years after diagnosis for all cohort members were excluded in the analysis.

\section{RESULTS}

30,373 cases out of the total 32,968 , which accounted for $92.1 \%$ of the total, were interviewed. Among them there were 19,709 males and 10,664 females. Infiltration was the predominant type of pulmonary tuberculosis at diagnosis, which accounted for $88.8 \%$ and $86.3 \%$ in males and females, respectively.

Table 1 presents SMRs with their $95 \%$ confidence intervals for all cancers and lung cancer alone among persons who had a history of lung tuberculosis. The SMRs for lung cancer along were 1.38 and 2.73 in males and females, respectively, both were statistically significant. No significant SMR was observed for all cancers both in males and females.

In order to eliminate the effect of smoking on risk of lung cancer in the cohort, we calculated SMRs for lung cancer among nonsmoking cohort members at the age of 40 and over observed during 1980-1988 by use of the age-sex-specific mortality rates for lung cancer among nonsmokers of general population in Shanghai urban during the period 1983-1986 as the standard (Table 2). The rates in Table 2 are cited from a prospective cohort study involving 110 thousand adults resided in Shanghai urban and grouped as smokers and non-smokers ${ }^{(2)}$. The result showed that SMRs for lung cancer were 1.72 (95\% CI: 1.11-2.53) in males and 2.79 (95\% CI: $1.79-4.14$ ) in females (Table 3), this implies that the elevated risk of lung cancer among persons who had a history of pulmonary tuberculosis was irrelevant to smoking.

For elucidating the effect of intake of isoniazid on occurrence of lung cancer, SMRs for lung cancer among cohort members were calculated by cumulative intake of isoniazid. 
Table 1 SMRs for all cancers and lung cancer alone among lung TB patients in Shanghai urban.

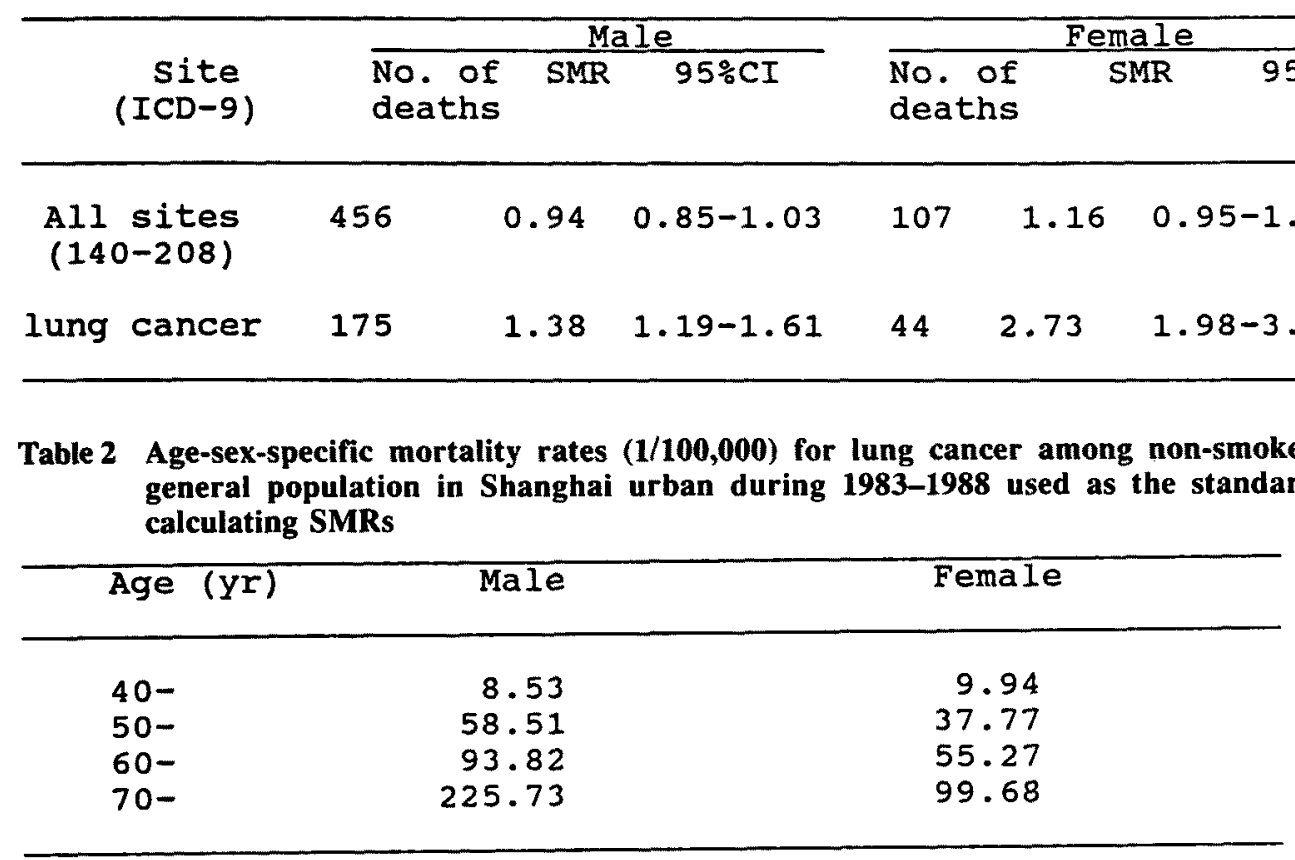

Table 3 Age-sex-specific mortality rates $(1 / 100,000)$ and SMRs lung cancer among nonsmoking lung TB patients in Shanghai urban (1980-1986)

\begin{tabular}{|c|c|c|c|c|c|c|}
\hline \multirow[b]{2}{*}{$\begin{array}{l}\text { Age } \\
\left(y^{\prime}\right)\end{array}$} & \multicolumn{3}{|c|}{ Male } & \multicolumn{3}{|c|}{ Female } \\
\hline & $\begin{array}{l}\text { Person- } \\
\text { Years }\end{array}$ & $\begin{array}{l}\text { No. of deaths } \\
\text { due to lung } \\
\text { cancer }\end{array}$ & Rate & $\begin{array}{l}\text { Person- } \\
\text { Years }\end{array}$ & $\begin{array}{l}\text { No. of } \\
\text { due to } \\
\text { cancer }\end{array}$ & $\begin{array}{l}\text { deaths } \\
\text { lung Rate }\end{array}$ \\
\hline $40-$ & 4658 & 1 & 21.47 & 7863 & 7 & 89.02 \\
\hline $50-$ & 5145 & 6 & 116.62 & 7976 & 8 & 100.30 \\
\hline $60-$ & 4359 & 12 & 275.29 & 4704 & 6 & 127.55 \\
\hline $70-$ & 3119 & 6 & 192.37 & 2210 & 3 & 135.75 \\
\hline $\begin{array}{l}\text { SMR: } \\
95 \% \mathrm{C}\end{array}$ & & $\begin{array}{c}1.72 \\
1.11-2.53\end{array}$ & & & $\begin{array}{c}2.79 \\
79-4.14\end{array}$ & \\
\hline
\end{tabular}

Higher SMRs were seen in all groups (Table 4), but by use of the trend test no statistically significant dose-response relationship between intake of isoniazid and occurrence of lung cancer was observed both in males and females. The result means that the higher risk of lung cancer can not be explained by use of the isoniazid. The similar result was also observed with regard to chest $\mathrm{X}$-ray exposure (Table 5). 
Table 4 SMRs for lung cancer among lung TB patients by cumulative intake of isoniazid

\begin{tabular}{|c|c|c|c|c|}
\hline \multirow{2}{*}{$\begin{array}{l}\text { Cumulative intake } \\
\text { of isoniazid(month) }\end{array}$} & \multicolumn{2}{|c|}{ Male } & \multicolumn{2}{|c|}{ Female } \\
\hline & SMR & $95 \% \mathrm{CI}$ & SMR & $95 \% \mathrm{CI}$ \\
\hline $\begin{array}{r}<7 \\
7-12 \\
13-18 \\
19-\end{array}$ & $\begin{array}{l}1.25 \\
1.28 \\
1.44 \\
1.50\end{array}$ & $\begin{array}{l}0.87-1.73 \\
0.91-1.76 \\
1.00-2.02 \\
1.16-1.91\end{array}$ & $\begin{array}{l}4.01 \\
3.22 \\
1.60 \\
2.11\end{array}$ & $\begin{array}{l}2.25-6.63 \\
1.71-5.51 \\
0.52-3.74 \\
1.05-3.78\end{array}$ \\
\hline
\end{tabular}

Trend test $x^{2}=1.0317,0.50>p>0.25: \quad x^{2}=3.6610,0.10>p>0.05$

Table 5 SMRs for lung cancer among lung TB patients by times of chest X-ray exposure

\begin{tabular}{|c|c|c|c|c|}
\hline \multirow{2}{*}{$\begin{array}{l}\text { Times of chest } \\
\text { X-ray exposure }\end{array}$} & \multicolumn{2}{|c|}{ Male } & \multicolumn{2}{|c|}{ Female } \\
\hline & SMR & $95 \% \mathrm{CI}$ & SMR & $95 \div \mathrm{CI}$ \\
\hline $\begin{array}{r}<5 \\
5-9 \\
10-14 \\
15-\end{array}$ & $\begin{array}{l}1.53 \\
1.34 \\
1.52 \\
1.15\end{array}$ & $\begin{array}{l}1.06-2.12 \\
1.04-1.69 \\
1.12-2.02 \\
0.74-1.72\end{array}$ & $\begin{array}{l}3.94 \\
2.97 \\
1.40 \\
3.01\end{array}$ & $\begin{array}{l}2.10-6.74 \\
1.65-4.28 \\
0.45-3.27 \\
1.21-6.20\end{array}$ \\
\hline
\end{tabular}

Trend test $x^{2}=0.5019,0.50>p>0.25 \quad x^{2}=1.5027,0.25>p>0.10$

\section{DISCUSSION}

The possible relationship between pulmonary tuberculosis (TB) and the subsequent development of lung cancer has attracted attention for several decades. There have been numerous clinical reports of concurrent lung cancer with TB, and of cancers, especially adenocarcinoma and peripheral tumours, arising from TB scars ${ }^{(3,4)}$.

The results of epidemiologic studies were not the same. Most of them have suggested a moderate increase in the risk of lung cancer among TB patients (1,5-10). The largest was a cohort study of 64,000 TB patients in Canada to evaluate the late effects of isoniazid ${ }^{(9)}$. A 1.5-fold excess risk of lung cancer was found in patients with TB as compared to the general population. Cohort studies in Australia ${ }^{(5,7)}$, Denmark ${ }^{(8)}$ and Israel ${ }^{(6)}$ revealed 2-fold or greater lung cancer risk among TB patients. 3 cohort studies in United States ${ }^{(11,13)}$ and United Kingdom $^{(12)}$ have not found an increase risk of lung cancer, although the numbers of expected case were not large. Information on smoking for cohort members was available only in one out of 8 cohort studies, this Australian study ${ }^{(7)}$ has suggested that the excess risk was not confound by smoking. A case-control study in Hawaii revealed an 8-fold excess risk of lung cancer in nonsmoking women with a history of TB, but only 4 cases were affected ${ }^{(10)}$. The recent population-based case-control study in Shanghai urban has found a 50\% elevation in the risk of lung cancer adjusted for smoking among persons with a history of TB. The elevated risk was not related to the use of isoniazid. The effect of recent tuberculosis was most apparent for adenocarcinoma and peripheral tumours ${ }^{(1)}$.

The retrospective cohort study reported in this paper has confirmed the result of abovementioned case-control study. In comparison to the general population a $38 \%$ and $173 \%$ elevation in the risk of lung cancer were observed in males and females with a history of TB. If only nonsmoking subjects were compared (non-smokers with a history of TB vs. non- 
smokers of general population), the elevation in risk of lung cancer were $72 \%$ and $179 \%$ in males and females, respectively.

In the excess risk found in this study real? Firstly, as mentioned above, the effect of mistake in diagnosis of lung cancer as pulmonary tuberculosis was greatly reduced by means of exclusion of all deaths occurred within three years after diagnosis, since the 5 year survival rate for lung cancer was low, only $7 \%$ in Shanghai urban ${ }^{(14)}$. Secondly, according to health policy of the government, medical service is easily available for most of the residents of Shanghai urban, it is hardly to believe that more cases of lung cancer as cause of death were undetected in the general population. Thirdly, the effect of smoking on lung cancer has been removed in the study. By use of the age-sex-specific mortality rates of lung cancer for nonsmoking population as the standard, the elevation in risk of lung cancer in females almost remained unchanged, which can be explained by the very low prevalence of smoking among females $^{(15)}$. In contrast with females the elevation in risk of lung cancer in males almost doubled, which probably has resulted from the high prevalence of smoking in general male population $^{(15)}$ with higher mortality rates of lung cancer used as the standard. After removing the effect of smoking the relationship between lung cancer and TB was further clarified. In addition, in this study the relationship was not relevant to the duration of intake of isoniazid nor to the frequency of chest X-ray exposure, the same results as indicated in the previous case-control study ${ }^{(1)}$.

Despite diverse explanations the precise mechanisms of the relationship are still unclear. However, since both the case-control study and cohort study in Shanghai urban have given the similar result, it is rational to consider persons with a history of TB as a high risk group for lung cancer. After taking large-scale systematic preventive measures against tuberculosis which was very prevalent among residents in the past, tuberculosis now is not an important health problem in Shanghai. If the link between lung cancer and prior TB is a causal one, it was estimated from calculation of attributable risk that TB would account for less than $10 \%$ of the lung cancers today in Shanghai ${ }^{(1)}$.

\section{ACKNOWLEDGEMENTS}

The authors thank the staff of Shanghai Antituberculosis Network in urban districts for their contribution in data collection for the study.

\section{REFERENCES}

1. Zheng, W., Blot, W.J., Liao, M.L. et al.: Lung cancer and prior tuberculosis infection in Shanghai. Br. J. Cancer, 56: 501, 1987.

2. Deng, J., Gao, Y.T., Wang, Z.X. et al.: Relationship between lung cancer, smoking and general air pollution- A prospective cohort study among 210,000 adult residents in Shanghai Municipality, in press.

3. Auerbach, O., Garfinkel, L., Parks, V.R.: Scar cancer of the lung, increase over a 21 year period. Cancer, 43: 636, 1979.

4. Bakris, G.L., Mulopulos, G.P., Korchik, R. et al.: Pulmonary scar carcinoma. Cancer, 52: 493, 1983.

5. Campbell, A.H.: The association of lung cancer and tuberculosis.Aust. J. Med., 10: 126, 1961. 
6. Steinitz, R.: Pulmonary tuberculosis and carcinoma of the lung.Am. Rev. Respir. Dis. (Suppl.), 92: 758, 1965.

7 Campbell, A.H., Guilfoyle, P.: Pulmonary tuberculosis, isoniazid and cancer. Br. J. Dis. Chest., 64: 141, 1970.

8. Clemmesen, J., Jensen, S.H.: Is isonicotine acid hydrazide (INH)carcinogenic to man? Ecotoxicol. Environ. Safety, 3: 439, 1979.

9. Howe, G.R., Lindsay, J., Coppock, E. et al.: Isoniazid exposure in relation to cancer incidence and mortality in a cohort of tuberculosis patients. Int. J. Epidemoiol., 8: 305, 1979.

10. Hinds, M.W., Cohen, H.I., Kolonel, L.N.: Tuberculosis and lung cancer risk in nonsmoking women. Am. Rev. Respir. Dis., 125: 776, 1982.

11. Hammond, E.C., Selikoff, I.J., Robitzek, E.: Isoniazid therapy in relation to later occurrence of cancer in adults and in infants.Br. Med. J., 2: 792, 1967.

12. Stott, H., Peto, J., Stephens, R. et al.: An assessment of the carcionogenicity of isoniazid in patients with pulmonarytuberculosis. Tubercle, 57: 1, 1976.

13. Boice, J.D., Fraumeni, J.J.Jr.: Late effects following isoniazid therapy. Am. J. Public Health, 70: 987, 1980.

14. Shanghai Cancer Institute: Analysis of cancer incidence, survival and mortality rates in Shanghai urban area. ShanghaiTumour, 2:1, 1982.

15. Deng, J., Gao, Y.T.: The prevalence of smoking habit among 110,000 adult residents in Shanghai urban area. Ch. J. Prev. Med., 5: 271, 1985. 